\title{
EFEITOS DE ESTIMULANTES VEGETAIS NA FRUTIFICAÇAO DO TOMATEIRO 'MIGUEL PEREIRA' *
}

MARISA VAZQUEZ CARLUCCI **

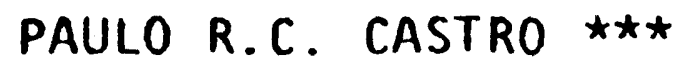

RESUMO

Na cultura do tomateiro tem-se utili zado tëcnicas avançadas de cultivo, sendo que a aplicação de estimulantes vegetais, usada como técnica com plementar, poderá levar a um aumentō significativo de produção. 0 presen te estudo teve como finalidade deter minar a ação de estimulantes vegetais na frutificação do tomateiroLycopersicon esculentum cv. Miguel Pereira. Em condições de casa de veget ação realizou-se a aplicação na planta inteira de Cytozyme bioesti mulante composto por citocinina, én=

* Entregue para publicação em 04/11/1982.

** Seção de Genética, Instituto Agronōmico do Estado de São Paulo, Campinas.

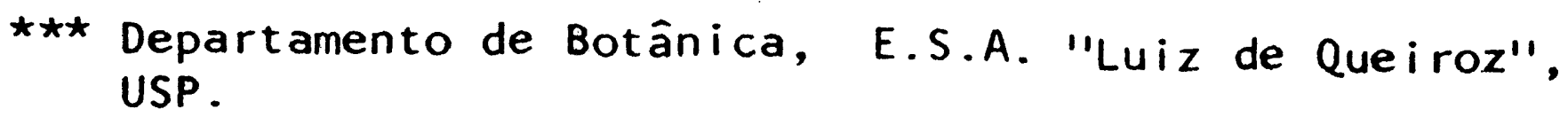


zimos, micronutrientes: $\mathrm{Zn}, \mathrm{Fe}, \mathrm{Cu}$, $\mathrm{Mn}$, Bo, combinados com derivados de etoxilato-siloxano e aminoácidosl e Ergost im (äcido $\mathrm{N}$-acetil tiazolidin4-carboxílico com ácido fölicol. Cytozyme $5 \mathrm{ml} / 1$ foi aplicado 70 dias após o plantio, aos 70 e 84 dias após plantio. Ergostim $1.5 \mathrm{ml} / \mathrm{l}$ foi pulverizado na florescência de cada cacho; e Ergostim 3,0 ml/1 na florescência, fixação dos frutos do segundo cacho e quando os mesmos atingiram metade do desenvolvimento. 0s fru tos maduros dos três primeiros cachos foram colhidos semanalmente em dez coletas no período de 07 de novembro a 09 de Janeiro. observou-se o número, peso e comprimento dos fru tos, assim como o número de flores $\bar{e}$ de flores abortadas. Determinou-se também a classificação dos frutos e a germinação das sementes. Foi veri ficado que Cytozyme $5 \mathrm{ml} / \mathrm{l}, 70$ e 84 dias após plantio aumentou o número e o comprimento dos frutos e o número total de flores. Ergostim não afetou a frutificação e floração do tomateiro, nem a formação e germina ção das sementes.

INTRODUÇÃO

A crescente procura-de produtos do tomate fez com que houvesse um aumento muito grande na produção mundial. No Brasil, tem-se verificado aumentos gradativos nas áreas cultivadas e melhorias na produtividade, devido basicamente ao emprego de cultivares melhorados aprimora mento das técnicas de cultivo. 
0 uso de reguladores e estimulantes vegetais em to mateiro, técnica comumente usada nos principais países produtores, não tem sido empregada entre nós com a mesma frequência devido ao pequeno número de ensaios montados para esclarecer as respostas da cultura nas condições tro picais.

IWAHORI (1968) observou o efeito do àcido giberéli co $\left(G_{3}\right)$, 6-benzilamino purina (BA) e PCPA na fixação dos frutos e produção de tomateiros em condições de alta tem peratura. Aplicando $B A+G A$ a $10 \mathrm{ppm}$, na antese ou na for mação dos botões florais, antes do tratamento com altas temperaturas, observou aumento na fixação dos frutos e na produção.

Segundo KAUSHIK et alii (1977), tomateiros pulveri zados com soluçōes de NAA, GA, cinetina e morfactina tiveram um aumento na produção. As plantas foram tratadas no estágio de duas a cinco folhas verdadeiras, com aplicaçōes semanais, nas dosagens de 1,10 ou $100^{\circ} \mathrm{mg} / 1$ dos re guladores vegetais. Cs tratamentos mais eficientes foram obtidos com baixas concentrações de NAA, cinetina e morfactina, sendo que a mais alta concentração de GA 3 mostrou-se mais promissora. Ao conträrio, altas concentraçōes de NAA, cinetina e morfactina reduziram marcadamente o número de frutos por planta. De acordo com BRYAN (1979), tratamentos com Cytex (uma fonte natural de cito cinina) em plantas de tomateiro, aumentaram as produçōes médias de frutos em 2,8 t/4047m². Aplicação de 1,91/4047 $\mathrm{m}^{2}$ através do sistema de irrigação, mais uma pulverização foliar no início da florescência, foi a mais promissora, aumentando as produções acima de $5 \mathrm{t} / 4047 \mathrm{~m}^{2}$.

JONES (1978) relatou que Cytozyme, composto de citocinina, énzimos, micronutrientes ( $\mathrm{Zn}, \mathrm{Fe}, \mathrm{Cu}, \mathrm{Mn}$ e Bo) combinados com derivados de etoxilato-siloxano e aminoācidos, mostrou-se promissor em estimular a frutificação de tomateiros. Além de melhorar a produção e induziruma maturação precoce e mais uniforme, esse bioestimulante a tuava em numerosas reaçōes da planta melhorando a percen tagem de germinação e emergência, proporcionando maior resistência das plântulas às condições desfavoráveis e 
aumentando o volume do sistema radicular e a absorção de nutrientes.

Segundo esse mesmo autor, pulverizaçōes de Cytozyme $(0,5+0,5) \quad 1 /$ ha 4 e 8 semanas após plantio e $0,51 /$ ha 4 semanas após plantio, aumentaram o número e peso dos frutos por planta de tomateiro além de melhorar a qualidade dos mesmos. Observou ainda que os melhores resultados quanto à produção e maturação foram conseguidos quando a aplicação do produto foi parcelada em duas vezes.

Segundo CASTR0et alii (1981), aplicação de Ergostim $0,75 \mathrm{ml} / 1$ durante a antese das primeiras flores dos 3 cachos, diminuiu o peso total e o peso médio dos frutos produzidos nos tomateiros tratados. Foi descrito tam bém que Ergostim na dosagem de 1,0 a $1,5 \mathrm{ml} / 1$ de āguá aplicado emtrês vezes, com intervalos de 12 dias, corres pondentes ao início da florescência dos três primeiros cachos do tomateiro, aumentou o peso total dos frutos, incrementando em $2000 \mathrm{~kg} /$ ha a produção total, melhorando ainda a classificação dos frutos sob a ação do bioestimu lante (DOSIO \& PADIN, 1978).

MATERIAIS E METODOS

0 experimento foi iniciado com a semeadura do tomateiro cultivar Miguel Pereira em Piracicaba a 16/07/79 em caixa de madeira com solo esterilizado, em condições de casa de vegetação. Efetuou-se o transplante em $08 / 08$ 179 para vaso de cerâmica com 14 litros de capacidade to tal e com 12 litros de terra, sendo 2 partes solo argilo so, I parte de areia e I parte matéria orgânica. Realizā ram-se os tratos culturais normais para a cultura do tomateiro.

Foram utilizados neste experimento o Cytozyme, assim denominado comercialmente, composto por citocinina, ênzimos, micronutrientes ( $\mathrm{Zn}, \mathrm{Fe}, \mathrm{Cu}, \mathrm{Mn}, \mathrm{Bo})$ combinados com derivados de etoxilato-siloxano e aminoácidos e o 
N-acetil tiazolidin-4-carboxílico com äcido fölico (Ergostim). Além do tratamento controle (A), efetuaram - se pulverizações de Cytozyme na dosagem de $5 \mathrm{ml} / 170$ dias após plantio (B), 70 e 84 dias após plantio (C) e de Ergostim $1,5 \mathrm{ml} / 1$ na florescência de cada cacho (D), e $3,0 \mathrm{ml} / 1$ na florescência e fixação dos frutos no 2 ? cacho e quando os mesmos atingiram metade do desenvolvimento (E). No controle foi aplicada somente água.

0 delineamento experimental foi inteiramente casua lizado com 10 repetições tendo-se mantido duas plantas por vasoe por repetição (correspondente a uma parcela), num total de 50 vasos. Procedeu-se à comparação de médias, pelo teste de Tukey, calculando-se a diferença mínima significativa (D.M.S.) ao nível de 5\% de probabilidade.

Realizaram-se dez colheitas semanais dos frutos ma duros dos trés primeiros cachos, durante o período de $07 / 11 / 69$ até a data de 09/01/80.

0 nümero, peso e comprimento dos frutos, assim como o nümero de flores e de flores abortadas, representam a soma dos valores das duas plantas por vaso por repetição. 0 peso dos frutos foi determinado com precisão de $0,1 \mathrm{~g}$, sendo o comprimento medido com paquímetro milimetrado. A percentagem de sementes viáveis ou inviäveis foi calculada em relação ao nümero total de sementes por repetição. Para classificação dos frutos, utilizaram-se caixas de madeira, com orifícios no fundo dediámetros ca nhecidos separando-se assim os frutos em classes ou ti= pos, da seguinte maneira: Extra A (diâmetro superior a 52 $\mathrm{mm}$ ), Extra (diâmetro entre 47-52 mm), Especial (diãmetro entre 40-47 mm), Superior (diâmetro entre 33-40 mm) e Di versos (diâmetro inferior a $33 \mathrm{~mm}$ ). Foram dadas notas correspondentes a cada classe com valores de 5 a 1 respectivamente, permitindo assim uma comparação estatísti ca das médias. Os testes quanto à percentagem de germi nação foram efetuadas segundo prescrição das Regras para Anälise de Sementes (ANONIMO, 1976).

Efetuou-se a anālise estatística para os parâme- 
tros referentes à produtividade, sendo que para a matura ção e colheita utilizou-se verificação gräfica.

\section{RESULTADOS E DISCUSSÃO}

Pelos resultados obtidos (Tabela 1), observa-se que o número de frutos produzidos mostrou-se superior nas plantas tratadas com Cytozyme $5 \mathrm{ml} / 1,70$ e 84 dias após plantio comparativamente às plantas controle. Esse resultado está de acordo com aqueles obtidos, em experimen tos realizados para verificarem a ação de compostos à bá se de citocinina, na frutificação do tomateiro. Destá maneira IWAHORI (1968) verificou aumento na fixação dos frutos e na produção de tomateiros tratados com BA+GA a 10 ppm na antese dos botões florais; sendo que KAUSHIK et alii (1977) observaram também uma maior produção com aplicaçäo de cinetina e morfactina em baixas concentrações no tomateiro. Usando Cytex (uma fonte natural de citocinina), BRYAN (1979) descreveu a ocorréncia de aumento de produção nos tomateiros tratados em relação às plantas controle. Aplicando Cytozyme, JONES (1978) veri ficou que o número de frutos por planta, assim como a produção total aumentou nos tomateiros tratados.

0 comprimento dos frutos mostrou-se superior nos tomateiros tratados com Cytozyme $5 \mathrm{ml} / \mathrm{l}, 70$ e 84 dias apōs plantio, em relação ao controle. Não se observou diferença significativa no comprimento dos frutos nas plantas tratadas com Ergostim e controle (Tabela 1).

Aplicação de Cytozyme $5 \mathrm{ml} / 1,70$ e 84 dias após plantio promoveu uma tendéncia de aumento no peso dos fru tos de tomateiro em relação ao controle (Tabela 1). J0NES (1978) também notou que Cytozyme provocou a formação de frutos mais pesados nas plantas tratadas. Pulverização com Ergostim no entanto, não afetou o peso dos frutos nas plantas tratadas em relação ao controle (Tabela 1). Concordando com os dados obtidos no presente trabaIho, CASTRO et alii (1981) verificaram que Ergostim 0,75 $\mathrm{ml} / \mathrm{l}$ aplicado na antese floral dos três cachos, diminuiu 


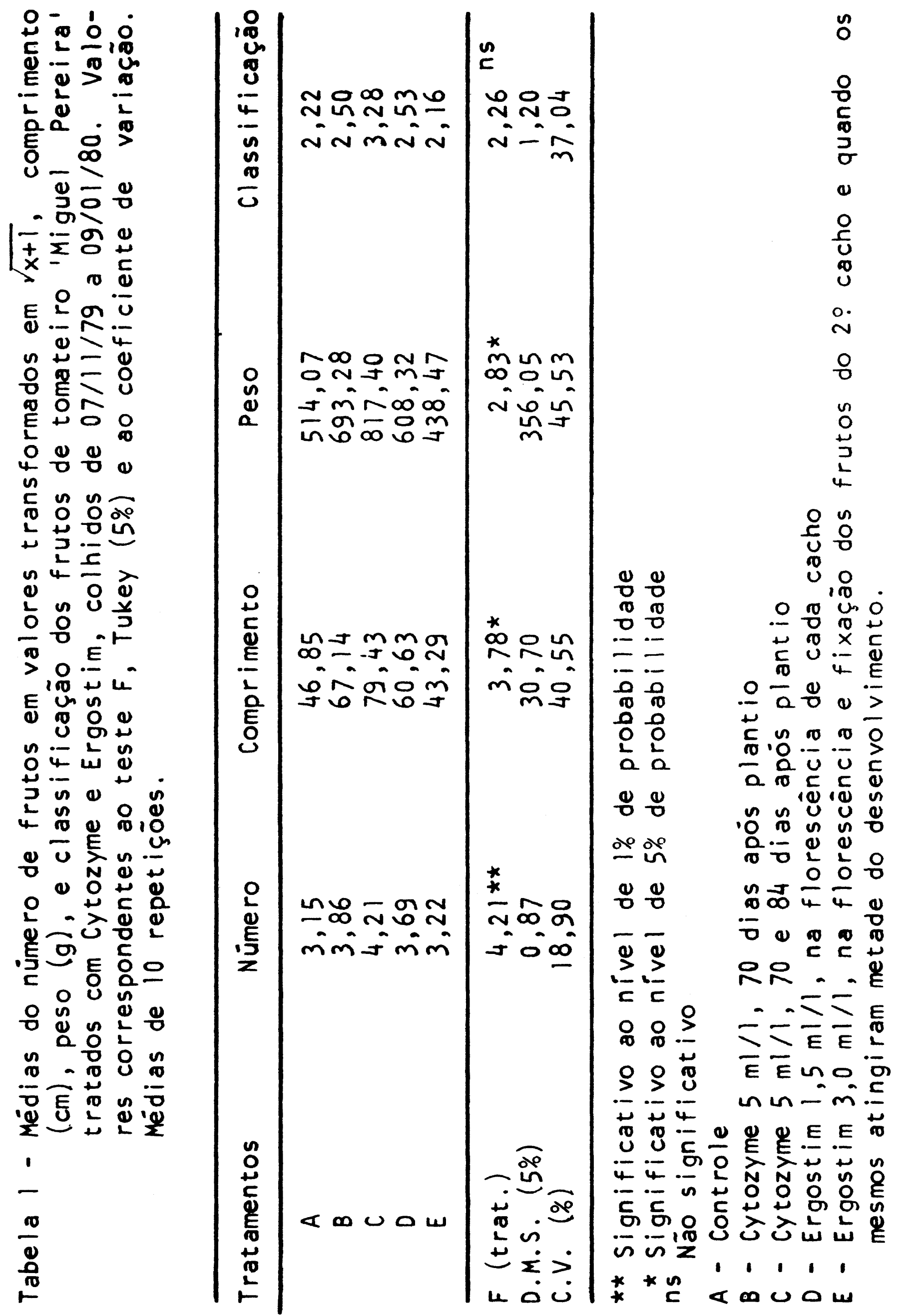




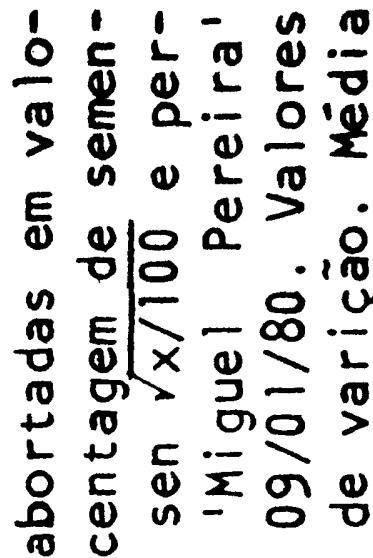

U⿺辶一兀 0

凹 ญ

ᄂ

$\frac{0}{4}$ 융

n 0 立

ชั

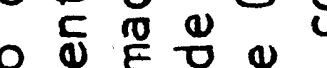

닌

E $>4$ 足

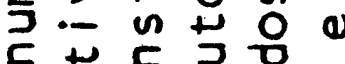

N 5 工

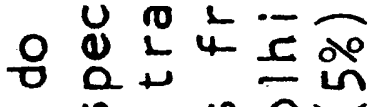

" n n

舫

O

$4 \not{x}$ ᄃ

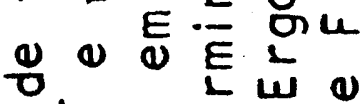

这的向

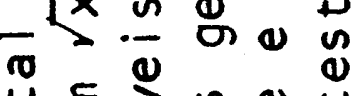

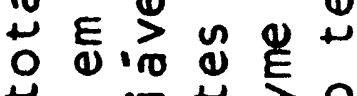

n

인음

\%

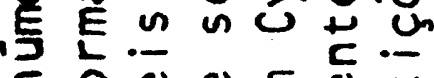

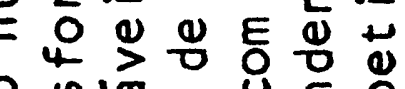
움

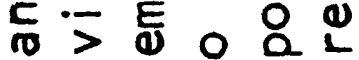

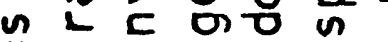

$\pi+. \pi$ to $\infty$

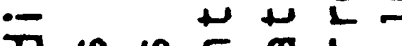

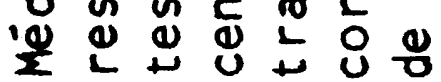

品

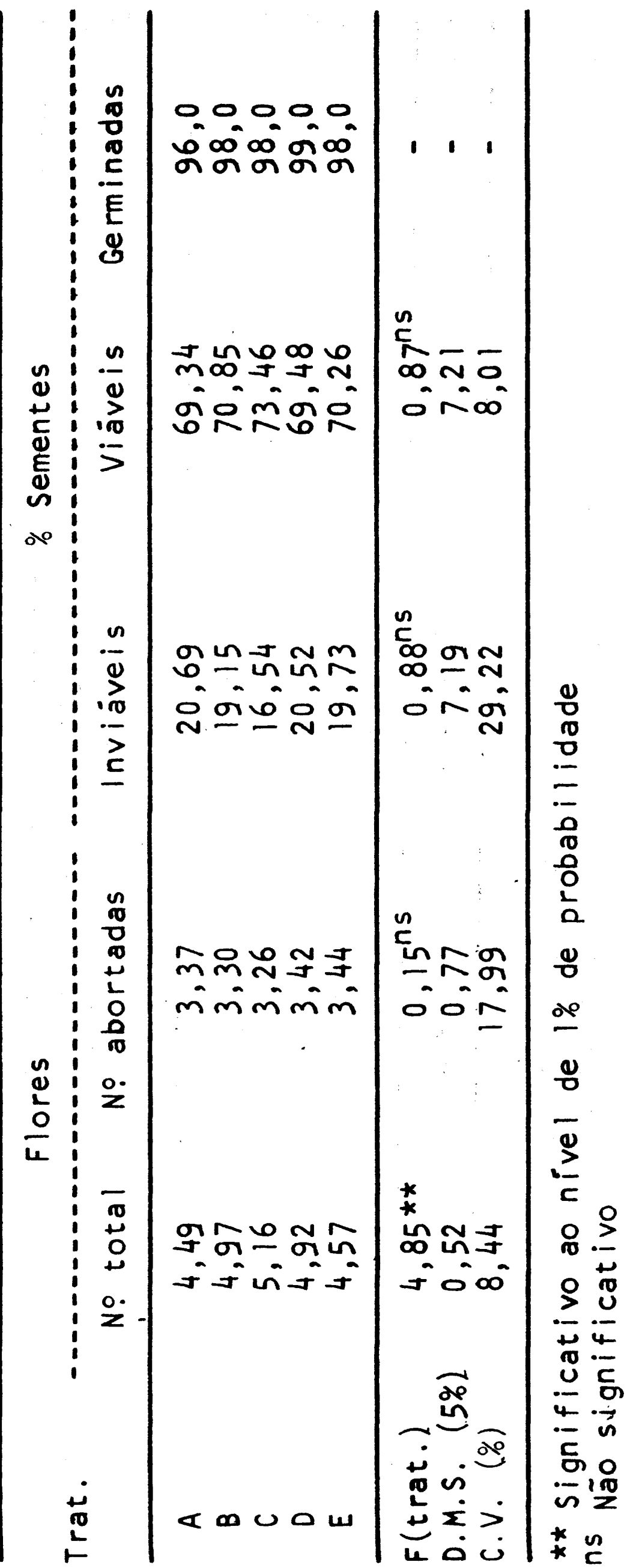


- peso total e o peso médio dos frutos produzidos. DOSIO E PADIN (1978) por sua vez, trabalhando com o cultivar Platense, observaram aumento no peso total dos frutos de tomateiros com aplicação de Ergostim 0,5 e $1 \mathrm{ml} / \mathrm{l}$, na florescência dos três primeiros cachos, discordando assim dos resultados obtidos no presente estudo.

Verificou-se pela análise dos dados obtidos para o número total de flores da planta de tomateiro, a presença de diferenças significativas entre os tratamentos. Ob servando-se as diferenças entre as médias notamos que as plantas tratadas com Cytozyme $5 \mathrm{ml} / 1,70$ e 84 dias após plantio mostraram maior número de flores com relação ao controle (Tabela 2).

0 nümero de flores abortadas e a porcentagem de se mentes inviáveis e viäveis não sofreram alterações sign $\bar{i}$ ficativas com aplicação dos reguladores vegetais (Tabela 2).

A maior produção total foi conseguida por Cytozyme $5 \mathrm{ml} / 170$ e 84 dias após plantio, na 5 a colheita que mos trou quase que o dobro do nümero de frutos maduros em com paração ao ponto máximo do controle ocorrido na 6 a coTheita.

\section{CONCLUSOES}

Dos resultados obtidos neste ensaio, podemos estabelecer as seguintes conclusões:

a) plantas tratadas com Cytozyme $5 \mathrm{ml} / 1,70$ e 84 dias após plantio produzem maior número de frutos e frutos de maior comprimento. 0 mesmo tra tamento aumenta o número total de flores;

b) aplicação de Ergostim não afeta a frutificação e floração do tomateiro, sendo que a formação e germinação das sementes também não é alterada pela aplicação do estimulante vegetal 


\section{SUMMARY}

\section{EFFECTS OF PLANT STIMULANTS ON THE FRUITING OF 'MIGUEL PEREIRA' TOMATO PLANTS}

This work was carried out to determine the effect of plant growth stimulants on the fruiting of tomato plant Lycopersicon esculentum cv. Miguel Pereira. In this trial Cytozyme (biostimulant composed of kinetin, enzimes, micronutrients: $\mathrm{Zn}, \mathrm{Fe}, \mathrm{Cu}, \mathrm{Mn}, \mathrm{Bo}$, combined with derivatives of siloxane-etoxilate and amino acids) and Ergostim (N-acetyl-thiazolidin-4-carboxilic acid plus folic acid) were sprayed as follows: Cytozyme at $5 \mathrm{ml} / 1$ was sprayed once at 70 days; twice, one at 70 and other 84 days after planting. Ergostim at $1,5 \mathrm{ml} / 1$ was sprayed once on the flowers of each cluster, and Ergostim at 3,0 $\mathrm{ml} / \mathrm{l}$ was sprayed three times, in the flowering, in the time of fruit set of the $2^{\text {nd }}$ cluster and when fruits attained one half of their development.

It was verified that Cytozyme $5 \mathrm{ml} / \mathrm{l}$ applied 70 and 84 days after planting, increased the number and the length of the fruits and the total number of flowers. Ergostim did affect neither flowering and fruiting of tomato plant nor the formation and germination of seeds.

\section{LITERATURA CITADA}

ANONIMO; 1976. Regras para anālise de sementes, Ministé rio da Agricultura, Brasília, DNPV/DMS, $188 \mathrm{p}$.

BRYAN, H., 1979. Cytokinins: a new production tool for tomato growers. Citrus and Vegetable Magazine 43: 36 37 .

CASTRO, P.R.C., PASTORE, J.C.; DEMETRIO, C.G.B., 1982. Efeitos reguladores vegetais na produtividade do tomateiro. An. Esc. Sup. Agric. "Luiz de Queiroz" 39: $181-188$. 
DOS10, L.J.; PADIN, S.B., 1978. Bio-estimulante Ergostim em cultivo de tomate. In: MONTEDISON DO BRASIL, Coord., Ergostim, São Paulo, Montedison do Brasil, p. $16-17$

IWAHORI, S., 1968. The effects of high temperature and growth regulating substances on fruit set and yield of tomato. Jour. Jap. Soc. Hort. Sci. 37: 143-147.

JONES, M.E., 1978. Tomato yield and maturity report on Cytozyme trials, Salt Lake City, Cytozyme Laboratories Inc., $5 p$.

KAUSHIK, M.P.; SHARMA, J.K.; INDRA, S., 1977. Effect of alpha-naphthaleneacetic acid, gibberellic acid, $k$ ine $t$ in and morphactin on yield of tomato. Plant Science 6: $51-53$. 
